\section{In-situ Investigation of the Microstructure Evolution in Long-Period-Stacking-Ordered (LPSO) Magnesium Alloys as a Function of the Temperature}

\author{
Kristián Máthis ${ }^{1,2 *}$, Daria Drozdenko ${ }^{2,3}$, Gergely Németh ${ }^{1,2}$, Stefanus Harjo ${ }^{4}$, Wu Gong ${ }^{5}$, \\ Kazuya Aizawa ${ }^{4}$, Michiaki Yamasaki ${ }^{3}$ and Yoshihito Kawamura ${ }^{3}$ \\ ${ }^{1}$ Nuclear Physics Institute, Czech Academy of Sciences, Prague, Czechia, ${ }^{2}$ Department of Physics of Materials, Faculty of \\ Mathematics and Physics, Charles University, Prague, Czechia, ${ }^{3}$ Department of Materials Science, Magnesium Research \\ Center, Kumamoto University, Kumamoto, Japan, ${ }^{4} \mathrm{~J}$-PARC Center, Japan Atomic Energy Agency, Ibaraki, Japan, ${ }^{5}$ Elements \\ Strategy Initiative for Structural Materials, Kyoto University, Kyoto, Japan
}

Deformation behavior of two Mg-Zn-Y magnesium alloys, having a different fraction of the long-period-stacking-ordered (LPSO) phase, has been investigated at room temperature and $200^{\circ} \mathrm{C}$ by a combination of in-situ neutron diffraction (ND) and acoustic emission (AE) measurements. The results indicate that the twinning in the magnesium matrix and the kinking in the LPSO phase strongly depend on the composition of the material and the testing temperature. Further, active deformation mechanisms and particularly the load transfer from the magnesium matrix to the LPSO phase define the mechanical properties of the investigated alloys.

Keywords: twinning, kinking, neutron diffraction, acoustic emission, LPSO phase

\section{INTRODUCTION}

Wrought magnesium $(\mathrm{Mg})$ alloys belong to the most promising lightweight materials in the transportation industry. However, there are many technological challenges, including tension-compression asymmetry in yielding and low formability at ambient temperature, which have to be solved for further expansion of $\mathrm{Mg}$ alloys usage. The rapid degradation of the mechanical properties with increasing temperature also significantly limits the application field. These issues have been addressed recently by developing $\mathrm{Mg}$ alloys with long-period-stacking-ordered (LPSO) phase, which is a periodic arrangement of close-packed atomic layers enriched by rear-earth elements and transition metals in the Mg lattice (Abe et al., 2011; Egusa and Abe, 2012). The presence of the LPSO phase significantly alters the deformation behavior of the material. Consequently, this class of alloys exhibits exceptional mechanical performance at room and high-temperature tests comparing to the commercial wrought Mg alloys (Inoue et al., 2001; Kawamura et al., 2001, 2006; Yamasaki et al., 2011). Owing to their higher Young modulus, the LPSO phase can bear the majority of the applied stress. Thus, the Mg-LPSO alloys behave like short-fiber-reinforced composites. Besides the dislocation slip and twinning, additional deformation mechanism, called kinking (sharp bending of the LPSO phase) is activated during the plastic deformation. All of them significantly depends both on materials parameters (volume fraction and orientation of the LPSO phase, the grain size of $\mathrm{Mg}$ matrix) and experimental conditions (loading direction, temperature etc.). There are numerous works investigating deformation mechanisms 
of such alloys at room temperature (e.g., Kishida et al., 2014; Garcés et al., 2018). Nevertheless, an in-depth understanding of deformation mechanisms (dislocation slip, kinking, and twinning) in Mg-LPSO based alloys as a function of temperature and volume fraction of the LPSO phase is still essential.

In this work, the microstructure evolution as a result of deformation behavior during uniaxial compression of two extruded $\mathrm{Mg}-\mathrm{Zn}-\mathrm{Y}$ alloy was investigated as a function of amount of the LPSO phase and the testing temperature. The neutron diffraction (ND) and concurrently recorded acoustic emission (AE) response were used to obtain detail information about active deformation mechanism in the alloys. The novelty of this work consists in comprehensive characterization of the activity of deformation twinning, kinking, and dislocation slip by a blend of in-situ methods. According to our current knowledge, this is the first ND study in the literature provided at elevated temperature on Mg-LPSO alloy. The results of the in-situ tests are completed by microstructure observation by light and scanning electron microscopy, particularly electron-backscatter diffraction (EBSD).

\section{EXPERIMENTAL}

Mg-3 at.\% Y-1.5 at.\% $\mathrm{Zn}$ and $\mathrm{Mg}-7$ at.\% $\mathrm{Y}-6$ at.\% $\mathrm{Zn}$ alloys extruded at $350^{\circ} \mathrm{C}$ with extrusion ratio $1: 10$ and ram speed of $2.5 \mathrm{~mm} / \mathrm{s}$ were investigated. The volume fractions of the LPSO phase in the investigated materials are $32 \%(\mathrm{Mg}-3$ at.\% $\mathrm{Y}-1.5$ at. $\% \mathrm{Zn}$ ) and $85 \%(\mathrm{Mg}-7$ at. $\% \mathrm{Y}-6$ at.\% $\mathrm{Zn}$ ), hereafter referred as
S32 and S85 alloys, respectively. Both, the initial and deformed microstructures were examined by confocal light (Lasertec C130) and scanning electron microscopes (SEM, JEOL, and JSM$7001 F)$ equipped with EDAX/TSL EBSD system. The specimens for the light microscopy observation were prepared by grinding and polishing down to $0.25 \mu \mathrm{m}$ diamond paste, followed by etching in picric acid for a few seconds. For EBSD measurements the final step of the preparation specimens after polishing using $0.25 \mu \mathrm{m}$ diamond paste was ion-milling (JEOL Cross Section Polisher SM-09010). For compression deformation tests, cylindrical specimens with a gauge length of $16 \mathrm{~mm}$ and diameter of $8 \mathrm{~mm}$ were machined along extrusion direction (ED). Loading was performed at a constant strain rate of $0.1 \mathrm{~mm} / \mathrm{min}$ at room temperature (RT) and $200^{\circ} \mathrm{C}$. The compression direction was parallel to ED and deformation test was terminated around $12 \%$ of strain in order to maintain the specimen's integrity. ND experiments were performed in-situ during compression using the engineering neutron diffractometer TAKUMI at Japan Proton Accelerator Research Complex (J-PARC). The specimens were fixed horizontally to a deformation rig with its axial direction at $+45^{\circ}$ to the incident neutron beam, and two detector banks are used to collect the diffracted neutron patterns at $+90^{\circ}$ and $-90^{\circ}$ relative to the incident beam, respectively. Concurrently, the AE activity was monitored by a MICRO-II AE system (Physical Acoustics Corporation) in hit-based mode, where the threshold level was set as $32 \mathrm{~dB}$. A preamplifier of $60 \mathrm{~dB}$ and sensors: a piezoelectric PICO S/N 7549 and a S9215 high temperature sensor for room and elevated temperature tests, respectively, were used.
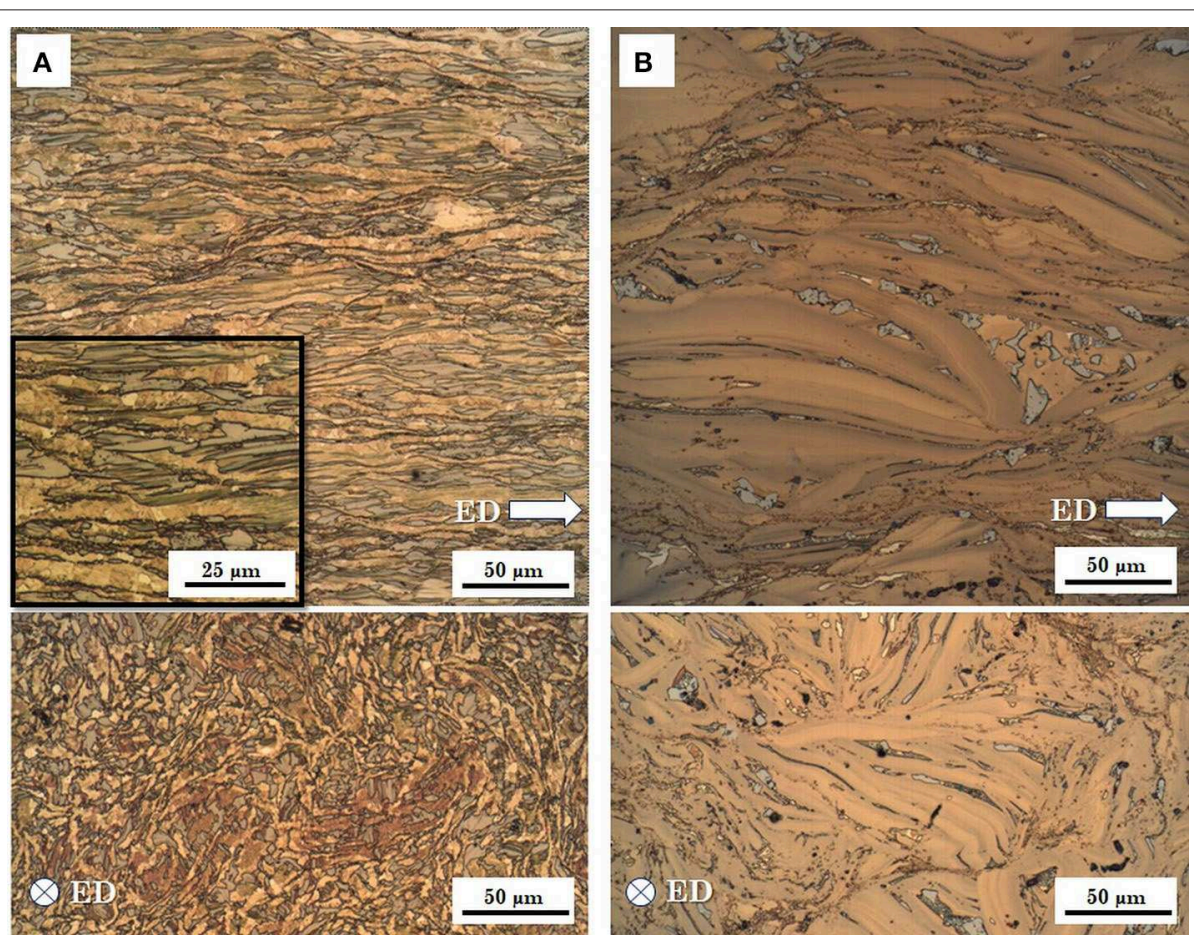

FIGURE 1 | The initial microstructure of the S32 (A) and S85 (B) alloys obtained by confocal light microscope along and perpendicular to ED. 


\section{RESULTS AND DISCUSSION}

\section{Initial Microstructure}

The initial optical micrographs of the S32 and S85 alloys are presented in Figure 1. In both alloys the extrusion process resulted in an elongated microstructure: some non-recrystallized grains in S32 alloy and LPSO laths in both alloys are oriented parallel to ED. Nevertheless, LPSO laths are wavy and, in some cases, do not follow perfectly ED. Moreover, in the S85 alloy due to higher alloying content, i.e., higher volume fraction of a LPSO phase, LPSO laths are naturally larger comparing to one in the S32 alloy. Figure 2 presents EBSD maps for S32 and S85 alloys, including Kernel Average Misorientation (KAM) maps for entire scan area and separated orientation maps for the $\alpha$ $\mathrm{Mg}$ and LPSO phase together with calculated texture for each fraction. The black areas in the particular maps correspond to the other phase or unclear identification of the phase by software. The KAM maps indicate high internal strain (green color) in the LPSO laths and large non-recrystallized grains (e.g., marked by the white circle in Figure 2A), while the majority of $\alpha$-Mg grains are characterized by low values of KAM (blue color). Therefore, it can be concluded that $\alpha-\mathrm{Mg}$ grains in both alloys are mainly recrystallized one.

In general, both alloys are characterized by prismatic fiber texture, having basal planes oriented parallel to ED. From Figure $2 \mathrm{~A}$ it can be seen that $\alpha-\mathrm{Mg}$ grains in S32 alloy are characterized by weak texture with a distribution of intensities along the arc between the $<10.0\rangle$ and $<11.0\rangle$ poles with maximum intensity at (10.0) pole. In the case of S85 alloy, amount of $\alpha-\mathrm{Mg}$ phase is dramatically reduced comparing with the S32 alloy. Therefore, presented orientation map for $\alpha-\mathrm{Mg}$ grains (Figure 2B) has a rather informative character due to relatively small scan area caused by the small grain size of those grains in contrast to LPSO laths in this material. Nevertheless, those grains are characterized by rather random orientation similar to $\alpha-\mathrm{Mg}$ grains in S32 alloy. The LPSO phase in both alloys is characterized by their prismatic $\{10.0\}$ plane oriented perpendicular to the ED. Therefore, it can be seen that the major texture components for each phase are comparable for both investigated alloys. Thus, the effect of texture on mechanical

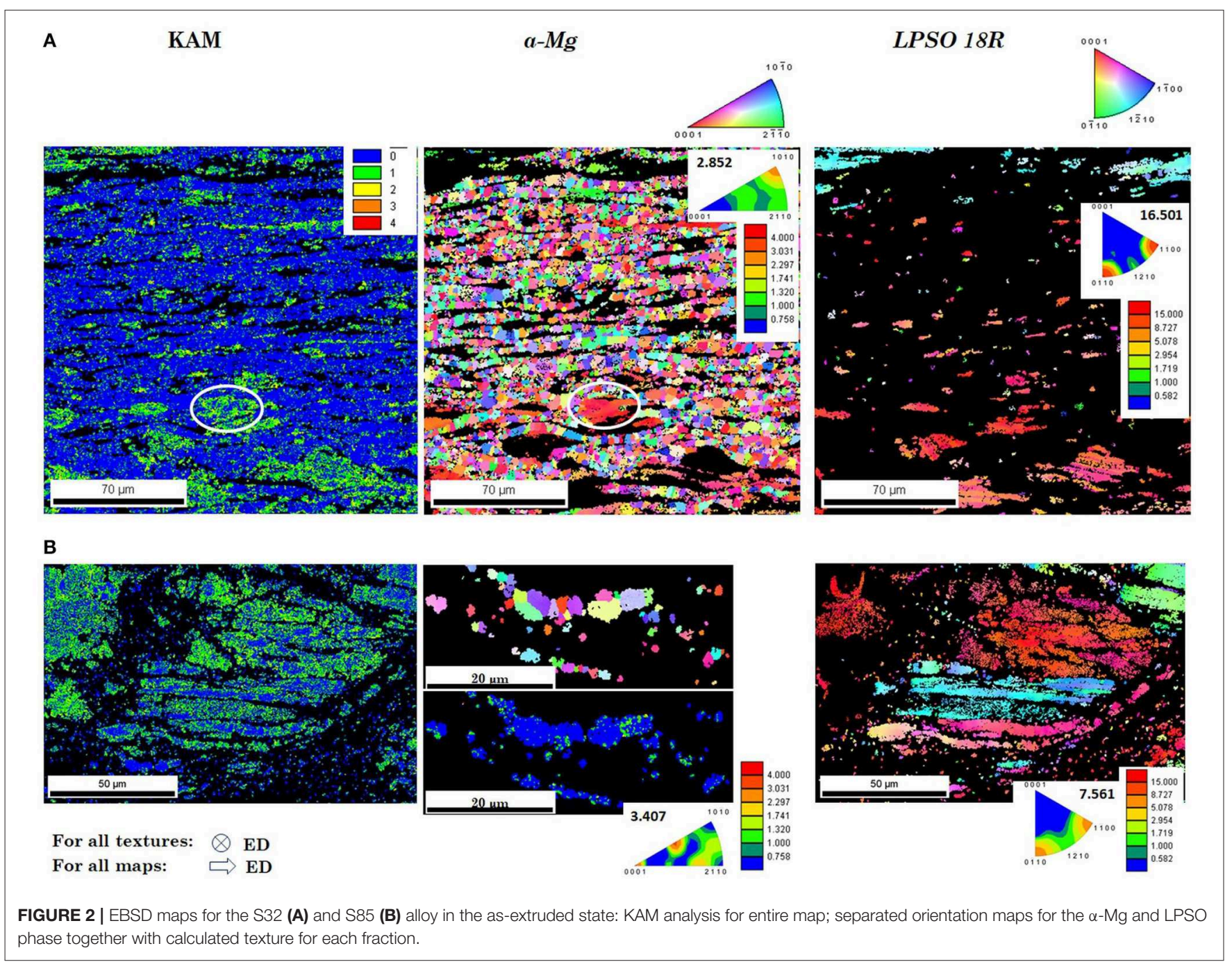




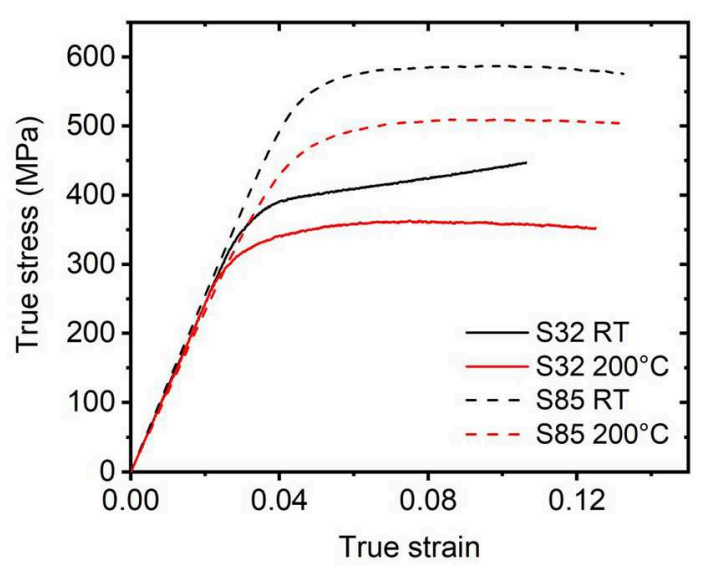

FIGURE 3 | True stress - true strain curves for S32 and S85 alloys tested in compression at room temperature and $200^{\circ} \mathrm{C}$.

properties in the present study is strongly linked to the volume fraction of the respective phase.

\section{Deformation Test}

The strong influence of the LPSO content and temperature on mechanical properties is obvious from Figure 3. At room temperature, the yield strength (YS) of S85 specimen is more than $30 \%$ larger (525 vs. $357 \mathrm{MPa}$ ) than that for S32 alloy. However, the character of the deformation curve is different. The S32 specimen exhibits an S-shape curve, characteristic for wrought alloys deformed in compression along ED, when the moderate hardening region (plateau) after the yield point is followed by a secondary hardening stage. At $200^{\circ} \mathrm{C}$ the value of YS decreases for both alloys (S32-305 MPa, S85-420 $\mathrm{MPa})$, but the degradation of mechanical properties is moderate (10 and 15\%, respectively). In both materials softening occurs above $6 \%$ of strain.

\section{Microstructure After Deformation}

The microstructure of the S32 and S85 alloys after deformation at RT and $200^{\circ} \mathrm{C}$ is presented in Figure 4. In the S32 alloy after RT deformation non-recrystallized grains are highly twinned (Figure 4A). The S32 alloy contains low fraction of LPSO phase, which has wavy, prolonged shape owing to the extrusion process. The kinking at room temperature in S32 alloy is less developed, and it appears mostly in form of bended LPSO laths (cf. Figure 14 in Garcés et al., 2018). This can be hardly distinguished from the initial wavy form of the LPSO phase in the presented optical micrographs. In contrast, deformation of the S85 alloy at RT is characterized by significant kinking (Figure 4B). At higher testing temperature (at $200^{\circ} \mathrm{C}$ ) kinking has been clearly observed also in the S32 alloy (detailed SEM image in Figure 4C). Moreover, with increasing deformation temperature, besides twinning and kinking, traces of the recrystallization process is observed (Figures 4C,D). Figure 4D includes a detailed EBSD map of the S85 alloys after deformation at $200^{\circ} \mathrm{C}$ showing small grains with low values of KAM, i.e., the DRX phenomenon for this alloy.

\section{Acoustic Emission Testing}

The acoustic emission was measured in the hit-based regime, when the raw acoustic emission signal was parametrized using a pre-set threshold level $(30 \mathrm{~dB})$ and hit definition time $(800$ $\mu \mathrm{s})$. The evolution of the count rate (number of crossing the threshold level by signal per second) with time is plotted for the particular specimens and testing temperatures in Figure 5. The AE response follows the characteristic behavior in $\mathrm{Mg}$ alloys. Already in the elastic regime there is a steep increment of the $\mathrm{AE}$ signal and after reaching the $\mathrm{YS}$, a significant drop of $\mathrm{AE}$ is observed. Closer analysis of the AE signal shows that it consists of large amplitude burst-type events. The "LPSO specific" feature is that the maximum of the $\mathrm{AE}$ count is reached far below the macroscopic yield. This behavior is characteristic for both investigated alloys and tested temperatures. It is obvious, that during RT loading maximum of $\mathrm{AE}$ count rate is higher for S32 alloy than that for S85 alloy. At $200^{\circ} \mathrm{C}$ the AE signal is weaker but the overall character of its behavior remains for both alloys.

\section{Neutron Diffraction Measurements}

The results of the ND experiments are presented in Figure 6, where for a particular specimen and temperature the stressstrain curves, stress dependence of lattice strains both for LPSO and $\alpha-\mathrm{Mg}$ phases are shown in one plot. Additionally, relative intensity changes for $\{10.0\} \mathrm{Mg}$ and $\{01.8\}$ LPSO peaks are shown. The reason for the selection of these peaks is given by the relationship of (00.2)-\{10.0\} peak pairs with twinning in $\alpha-\mathrm{Mg}$ phase (Gharghouri et al., 1999) and high intensity (i.e., good statistics) and no overlapping of $\{10.8\}$ LPSO peak with other Mg peaks. In S32 specimen at RT both the Mg and LPSO phase follows the line of the ideal elastic response up to 300 $\mathrm{MPa}$. Above this level, a microplasticity can be observed in $\mathrm{Mg}$ phase, connected most probably with the onset of the extension twinning and basal slip. At $360 \mathrm{MPa}$ significant relaxation of the lattice strain in $\mathrm{Mg}$ phase takes place. At the same time, the intensity of the $\{10.0\} \mathrm{Mg}$ peak sharply decreases, which is a clear sign of the massive twin growth. The stress dependence of the lattice strain on the LPSO planes indicates that the majority of the applied stress is bear by the LPSO phase. The behavior of the S85 specimen at RT is quite different (Figure 6B). Above $200 \mathrm{MPa}$ the LPSO phase exhibit plastic behavior, whereas the lattice strain evaluation of $\mathrm{Mg}$ phase is linear up to $480 \mathrm{MPa}$. In line with these findings, the intensity of the $\{01.8\}$ LPSO peak decreases above $200 \mathrm{MPa}$, which can be associated with the onset of the kinking process. At the same time, the change of relative intensity for $\{10.0\}$ peak is minimal comparing to that for S32 alloy and goes along with changes of intensity of the $\{01.8\}$ LPSO peak. Therefore, the decrease of the relative intensity of $\{10.0\} \mathrm{Mg}$ peak in S85 alloy can be associated with kinking rather than with twinning. It is obvious, that the intensity change caused by kinking is less sharp than that due to twinning. This is given by the gradual rotation of the lattice during the 


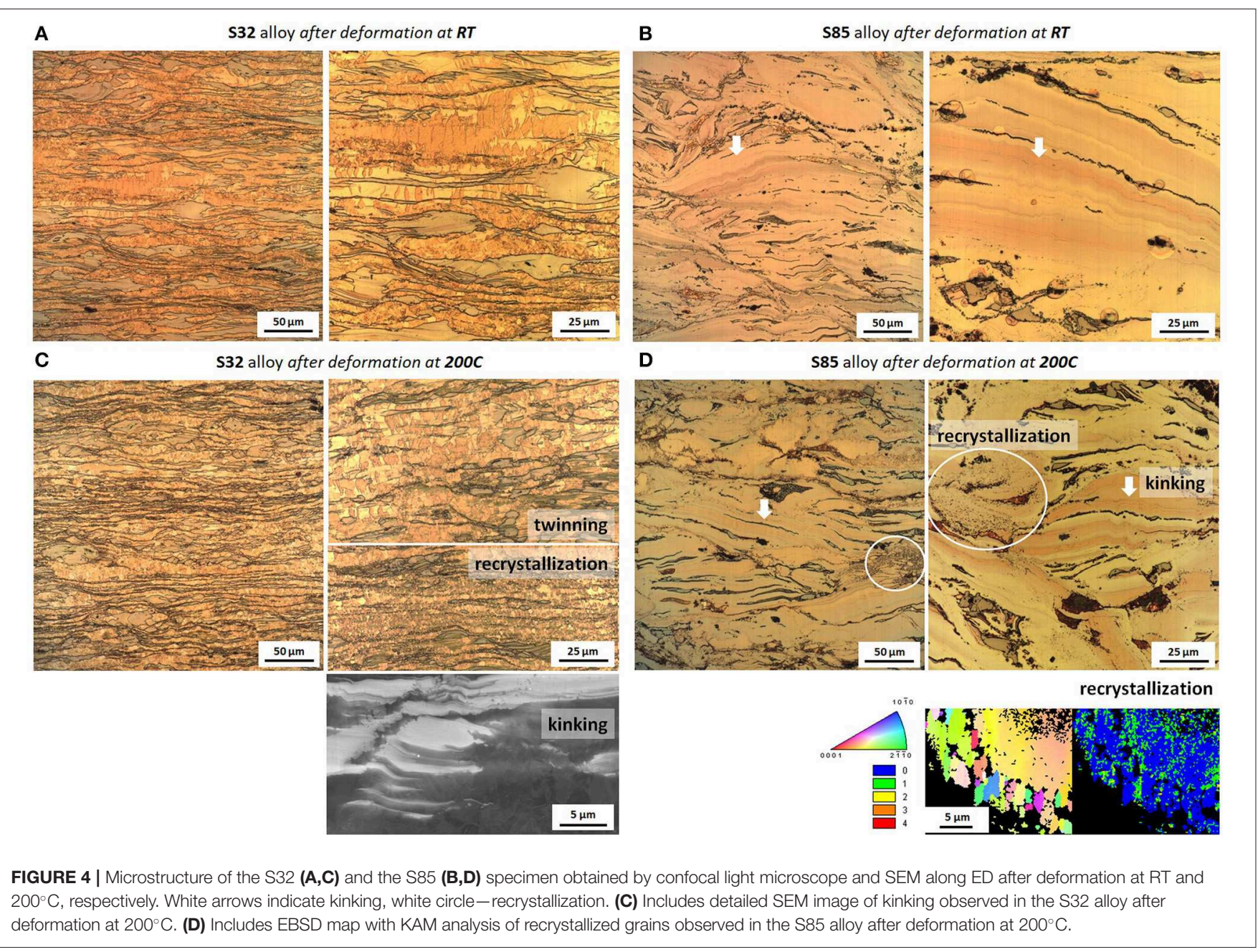

kinking in contrast to the $86.3^{\circ}$ lattice re-orientation during extension twinning.

At $200^{\circ} \mathrm{C}$ in $\mathrm{S} 32$ specimen the (micro)plasticity starts already below $100 \mathrm{MPa}$ (Figure 6C), which is in good agreement with our previous results (El-Tahawy et al., 2019). The behavior of the LPSO peaks indicates temperature enhanced dislocation activity: lattice strains deviate from a linear response at lower stress comparing to RT case, what theoretically can promote kinking. Due to small amount of LPSO phase, the relative intensity of $\{10.8\}$ LPSO peak does not show significant difference comparing to that at RT. At the same time, an intensity of the $\{10.0\}$ Mg peak sharply decreases at yield point indicating twinning activity. Moreover, the deviation of lattice strain for LPSO and $\alpha-\mathrm{Mg}$ phases from linear behavior may be affected by the recrystallization process. In the case of the S85 alloy, thermal activation also plays an important role. Gradual deviation from linearity is observed for LPSO peaks from the beginning of deformation, and for the $\mathrm{Mg}$ phase, a significant change for relative intensity of $\{10.0\}$ peak is observed after reaching 200 $\mathrm{MPa}$ (Figure 6D). Similar to RT loading, deviation of relative intensity change of the $\{10.0\} \mathrm{Mg}$ peak is accompanied by changes of the $\{01.8\}$ LPSO peak with little delay (one measuring point). Therefore, it can be concluded that changes of $\{10.0\} \mathrm{Mg}$ peak are related to the kinking process.

\section{DISCUSSION}

It is clearly seen that the volume fraction of the $\alpha-\mathrm{Mg}$ (nonand recrystallized grains) decreases with the increasing volume fraction of the LPSO phase, which strongly depends on the amount of alloying elements. Both investigated alloys are characterized by prismatic fiber texture. The alignment of the (10.0) plane in the ED can be explained by the lattice rotation due to non-basal slip with the $<11.0>$ slip direction during extrusion process (Mayama et al., 2011). Such texture is usually given by elongated worked grains having $<10.0>$ axis parallel to $\mathrm{ED}$, as it was previously reported for common wrought Mg alloys (Sillekens and Bohlen, 2012) as well as for Mg-LPSO materials (Hagihara et al., 2010a; Jono et al., 2013). In our case, most of an elongated worked grains experienced recrystallization during the extrusion process, and only a minority of non-recrystallized 

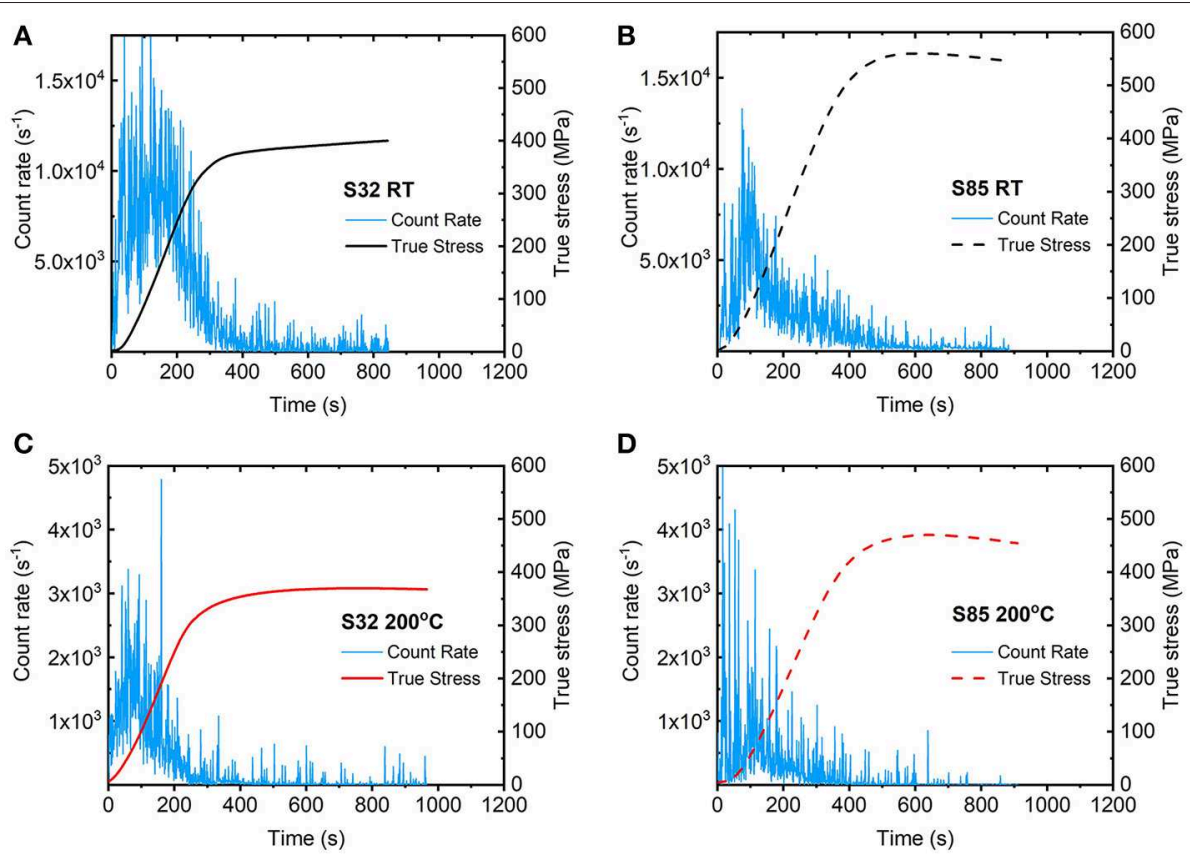

FIGURE 5 | The evolution of the AE count rate with time during compression loading of the S32 and S85 alloys at RT (A,B) and at $200^{\circ} \mathrm{C}(\mathbf{C}, \mathbf{D}$, respectively).

grains remains in the microstructure. Despite the fact that the majority of $\alpha-\mathrm{Mg}$ grains in the S32 alloy are fine recrystallized grains having preferentially a random orientation, a general characteristic of the texture persists. In the case of S85 alloy, detail EBSD maps indicate a random texture of recrystallized grains. Further, due to the concentration of high KAM values in non-recrystallized $\alpha-\mathrm{Mg}$ grains and LPSO laths, S32 alloy is characterized by significantly lower overall internal stress, comparing to that in S85 alloy containing $85 \%$ of LPSO phase. The described difference in internal strain has an impact on active deformation mechanisms. The high internal strain in the grains leads to increased stress values for slip activation (Farkas et al., 2017), i.e., high yield stress can be reached as in case of $\$ 85$ alloy.

The main sources of the AE in the Mg-LPSO alloys are the collective dislocation motion, twinning, kinking and failure mechanisms (cracking, delamination) and they are connected with the presence of the LPSO lath and its properties (volume, size, orientation etc.). For investigated alloys at both tested temperatures characteristic for $\mathrm{Mg}$ alloys $\mathrm{AE}$ count rate peak at the vicinity of yield point is observed. Usually, it has been explained by collective dislocation motion of dislocation (Heiple and Carpenter, 1987a) e.g., basal $<\mathrm{a}>$ dislocations as the easiest for activation due to lowest CRSS within deformation mechanism for Mg alloys (Bakarian and Mathewson, 1943). With the proceeding of plastic deformation, dislocation density increases and therefore, the free path of moving dislocation decreases, what leads to decrease of $\mathrm{AE}$ response. In the case of twinning activity, twin boundaries are also obstacles for freely dislocation movement and propagation of AE. However, it should be noted that twin nucleation itself (including propagation, i.e., growth in length) is an excellent source of AE (Toronchuk, 1977; Heiple and Carpenter, 1987b; Drozdenko et al., 2019) producing burst events with high amplitude, while twin growth (twin thickening) does not produce detectable AE (Vinogradov et al., 2016; Drozdenko et al., 2019). It was explained by the fact that the twin propagation is several order faster process than the twin growth (Vinogradov et al., 2016). At the same time, statistical analysis of AE signal in Mg-LPSO alloys has shown that kinking has similar characteristics to twinning (Garcés et al., 2018) and it can be also a source of burst high amplitudes AE events. Therefore, observed high amplitude burst AE events originate in twin nucleation and kinking. Moreover, recently Vinogradov et al. (2019) proposed a phenomenological approach for explanation the origin of $\mathrm{AE}$ count rate maximum around yielding through the relationship between $\mathrm{AE}$ power and dislocation density during dislocationmediated plastic deformation in some face-centered cubic metals with different stacking fault energies. Thus, dislocation kinetics in investigated Mg-LPSO alloys in present work can explain the appearance of AE peak already before yielding.

The AE data analysis presented here does not allow to separate the signals from the different sources. Nevertheless, it can serve as an indicator of the onset of the particular deformation mechanisms. In the case of the S32 alloy deformed at both RT and $200^{\circ} \mathrm{C}$, the strong $\mathrm{AE}$ at low stresses is connected with the twinning. The twin nucleation starts in the non-recrystallized grains and continues in small recrystallized one. Grain size dependence of twin nucleation studied by AE have been reported previously for Mg- (Dobron et al., 2011; Drozdenko et al., 2016) and Mg-LPSO alloys (Garcés et al., 2018). In case of S32 alloy deformed at RT, the maximum of $\mathrm{AE}$ count rate around $150 \mathrm{MPa}$ (Figure 5A), whereas the lattice strain relaxation takes place in Mg phase grains above $300 \mathrm{MPa}$ (Figure 6A). Later, a decrease 

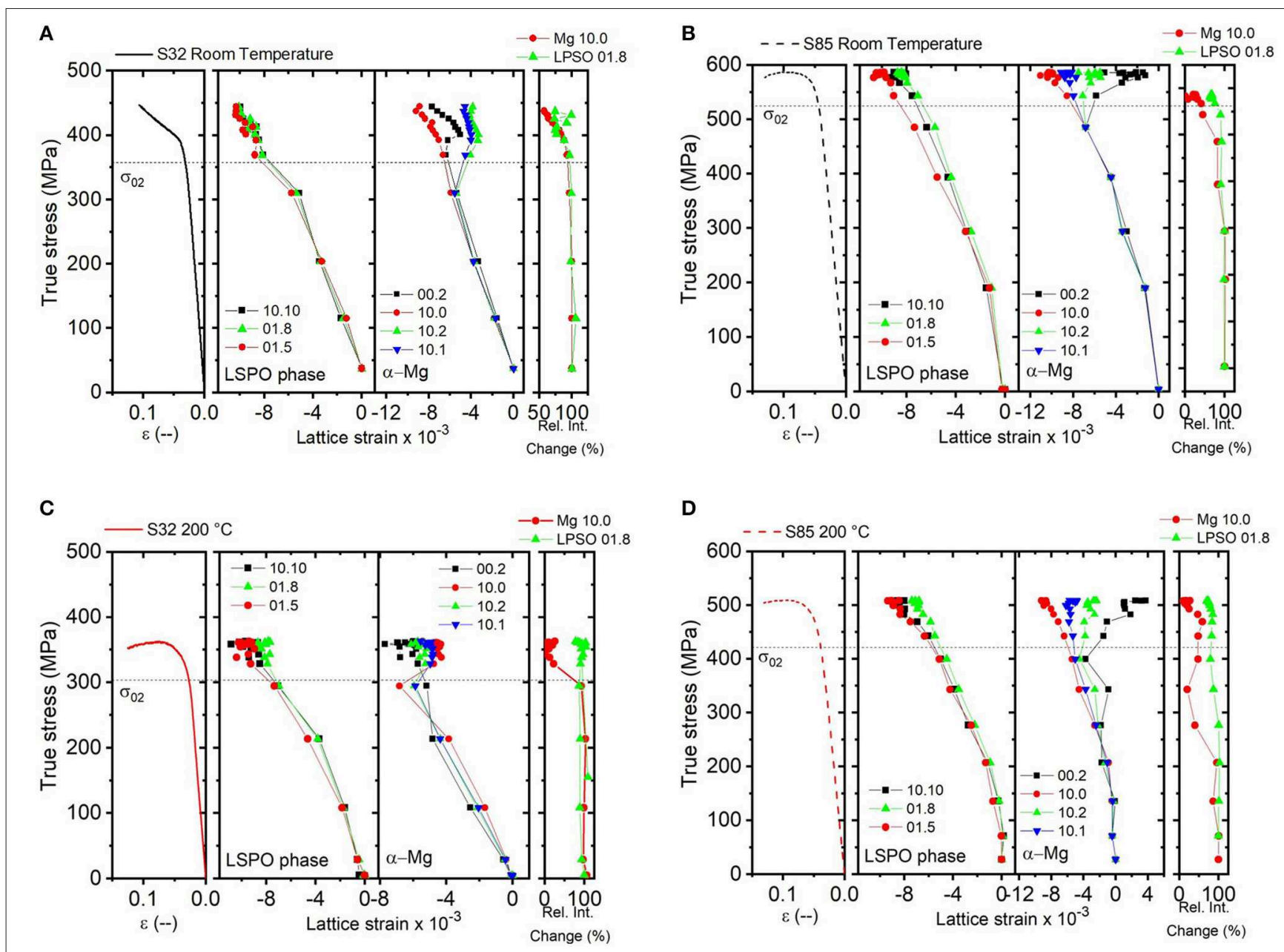

FIGURE 6 | Macroscopic stress-strain curves, the axial lattice strains as a function of the applied stress and evolution of the intensity of the major diffracted peaks of the $\alpha-M g$ and LPSO phase during compression loading of the S32 and S85 alloy at RT (A,B) and at $200^{\circ} \mathrm{C}(\mathbf{C}, \mathbf{D}$, respectively).

of $\mathrm{AE}$ count rate begins around $300 \mathrm{MPa}$, where the intensity of the $\{10.0\}$ peak connected with the twinning starts to change. This difference in the detection of the twinning by $\mathrm{AE}$ and $\mathrm{ND}$ can be explained as follows: the $\mathrm{AE}$ can detect signal from a very low number of twins (2-3) even in bulk specimen. However, as it was mentioned above only the twin nucleation can be detected by AE. In contrast, the ND detect only twin growth and owing to the uncertainty in diffraction peak determination a larger specimen volume has to be twinned in order to reveal the twin growing process. Consequently, since these two methods detect the various stage of the twinning process, the appearance of its contribution in $\mathrm{AE}$ and $\mathrm{ND}$ results are shifted (AE count rate peak appears before a characteristic change in ND data). Finally, the results of AE and ND measurements are supported by microstructure observation (Figure 4A) showing highly twinned microstructure in S32 alloy deformed at RT.

During deformation at a higher temperature, recrystallization and twinning are active concurrently. In this case, twins can be a nucleus for the recrystallization process (Basu and AlSamman, 2015, 2017; Guan et al., 2019). In Mg-LPSO alloys a particle-stimulated nucleation (PSN) process can control the recrystallization process (Oñorbe et al., 2012). With increasing temperature CRSS for other deformation mechanisms decreasing, therefore, twinning loses its dominance. Suppressed twining activity at higher temperature results in decreased $\mathrm{AE}$ count rate maximum (Figure 5C). Moreover, the decrease in $\mathrm{AE}$ response with increasing testing temperature is a commonly observed phenomenon in Mg alloys (Mathis et al., 2006) and can be explained by temperature promoted activation of other deformation mechanisms. It should be admitted, that with increasing deformation temperature, progressed kinking can be observed in S32 alloy. It is supposed that temperature promoted dislocation slip stimulates kinking.

Owing to the initial texture the basal slip is difficult for both alloys. In case of S32 alloy with majority $\alpha-M g$ grains, twinning as an additional deformation mechanism plays an important role in plastic deformation. In $\mathrm{Mg}$ alloys with a high volume fraction of LPSO twinning is rather rarely observed (Kishida et al., 2014). Therefore, in our S85 alloy with $85 \%$ of LPSO twinning is not expected deformation mechanism. In this case, 
high stress concentration is necessary for another than basal slip initiation-most probably prismatic slip. The prismatic slip in S85 alloy causes crystal rotation of basal planes toward the axial detector (Mayama et al., 2011). It can explain the deviation of LPSO peaks already before yielding (Figure 6B). Further, the first order $\{10.1\}<1-1.3>$ pyramidal slip becomes active, which causes peak shift and deviation of lattice strain of $\{10.10\}$ LPSO peak. As it was shown by Matsumoto et al. (2013), the pyramidal slip activates basal slip, which finally leads to kinking. Thus, load transfer from the $\alpha-\mathrm{Mg}$ matrix in S32 alloy to the LPSO phase in S85 alloy: from twinning to kinking as a dominant deformation mechanism, defines the mechanical properties of the investigated alloys, particularly higher YS in S85 comparing to S32 alloy. Kinking requires collective movement of a large number of basal dislocations (Hagihara et al., 2010b), thus it is followed by high emission of elastic waves. Consequently, kinking can explain a gradual change of lattice strain of LPSO peaks as well as concurrently recorded high amplitude AE. At the same time, owing to the kinking process, the diffracted planes come out from their Bragg position and the relative intensity of $\{01.8\}$ LPSO peak decreases.

The similar tendency is observed at the deformation of S85 alloy at $200^{\circ} \mathrm{C}$. However, changes in relative intensity of $\{10.0\}$ $\mathrm{Mg}$ peak and $\{01.8\}$ LPSO peak become significant at lower stress values comparing with RT test. It should be noted that the change in $\{10.0\} \mathrm{Mg}$ peak at $200 \mathrm{MPa}$ does not relate to twinning activity, but to kinking. Therefore, it can be concluded that indeed temperature promoted dislocation slip stimulates kinking. Similar to S32 alloy, recrystallization also takes a place. The nonbasal slip plays here an important role, and more detailed analysis of diffraction and AE data is necessary.

Obtained results show that temperature promoted changes in the dominant activity of deformation mechanisms (promoted dislocation slip and kinking, suppression of twinning) result in only moderate degradation of mechanical properties with increasing temperature. For instance, the S32 alloy with $32 \%$ of LPSO exhibits yield stress of $305 \mathrm{MPa}$, what is still acceptable value for $\mathrm{Mg}$ alloys. It stimulates further investigation of Mg-LPSO alloys as potential material for usage at high temperature.

\section{CONCLUSIONS}

The deformation behavior of two Mg-LPSO alloys having 32 and $85 \%$ LPSO volume content was investigated by insitu neutron diffraction and acoustic emission methods. The following conclusions can be drawn:

- Temperature increase results in only moderate degradation of mechanical properties;

\section{REFERENCES}

Abe, E., Ono, A., Itoi, T., Yamasaki, M., and Kawamura, Y. (2011). Polytypes of long-period stacking structures synchronized with chemical order in a dilute Mg-Zn-Y alloy. Philos. Mag. Lett. 91, 690-696. doi: 10.1080/09500839.2011.609149
- load transfer from the $\alpha-M g$ matrix to the LPSO phase, i.e., from twinning to kinking as a dominant deformation mechanism, defines the mechanical properties of the investigated alloys, particularly higher yield strength in alloys having $85 \%$ of LPSO comparing with alloy having $32 \%$ of LPSO;

- with increasing temperature recrystallization takes place $\alpha-\mathrm{Mg}$ in both materials;

- in Mg-LPSO with $32 \%$ of LPSO twinning is the main deformation mechanisms in $\alpha-\mathrm{Mg}$, and with increasing deformation temperature other deformation mechanisms become active at the expense of twinning due to reducing their CRSS;

- kinking is the main deformation mechanism in alloy with $85 \%$ of LPSO. Neutron diffraction data indicated that thermally activated dislocation slip is supposed to promote activation of kinking at lower stress.

\section{DATA AVAILABILITY STATEMENT}

The datasets analyzed for this study is available from the corresponding author, $\mathrm{KM}$, upon reasonable request.

\section{AUTHOR CONTRIBUTIONS}

KM and DD are the authors of the manuscript, performed the experiments, and evaluate the data. $\mathrm{GN}, \mathrm{SH}, \mathrm{WG}$, and $\mathrm{KA}$ contributed to the ND measurements and data evaluation. MY and YK provided the materials.

\section{FUNDING}

This research was funded by Czech Science Foundation grant number 18-07140S, and by the JSPS KAKENHI Grant Nos. JP17H03431 and JP18H05476. KM acknowledges the support of the Operational Programme Research, Development and Education, The Ministry of Education, Youth and Sports of Czech Republic (OP RDE, MEYS) [CZ.02.1.01/0.0/0.0/16_013/0001794]. The neutron diffraction experiments at the Materials and Life Science Experimental Facility of the J-PARC was performed under project No. 2018A0183.

\section{ACKNOWLEDGMENTS}

The authors acknowledge the help of Dr. Gergely Farkas in ND data evaluation.

Bakarian, P. W., and Mathewson, C. H. (1943). Slip and twinning of magnesium single crystals at elevated temperatures. Trans. AIME 152, 226-254.

Basu, I., and Al-Samman, T. (2015). Twin recrystallization mechanisms in magnesium-rare earth alloys. Acta Mater. $\quad$ 96, 111-132. doi: 10.1016/j.actamat.2015. 05.044 
Basu, I., and Al-Samman, T. (2017). Competitive twinning behavior in magnesium and its impact on recrystallization and texture formation. Mater. Sci. Eng. A 707, 232-244. doi: 10.1016/j.msea.2017.09.053

Dobron, P., Chmelik, F., Yi, S. B., Parfenenko, K., Letzig, D., and Bohlen, J. (2011). Grain size effects on deformation twinning in an extruded magnesium alloy tested in compression. Scr. Mater. 65, 424-427. doi: 10.1016/j.scriptamat.2011.05.027

Drozdenko, D., Bohlen, J., Yi, S., Minárik, P., Chmelík, F., and Dobron, P. (2016). Investigating a twinning-detwinning process in wrought $\mathrm{Mg}$ alloys by the acoustic emission technique. Acta Mater. 110, 103-113. doi: 10.1016/j.actamat.2016.03.013

Drozdenko, D., Capek, J., Clausen B, Vinogradov, A., and Máthis, K. (2019). Influence of the solute concentration on the anelasticity in $\mathrm{Mg}$ Al alloys: a multiple-approach study. J. Alloy Compd. 786, 779-790. doi: 10.1016/j.jallcom.2019.01.358

Egusa, D., and Abe, E. (2012). The structure of long period stacking/order Mg-ZnRE phases with extended non-stoichiometry ranges. Acta Mater. 60, 166-178. doi: 10.1016/j.actamat.2011.09.030

El-Tahawy, M., Máthis, K., Garcés, G., Matsumoto, T., Yamasaki, M., Kawamura, Y., et al. (2019). Type and density of dislocations in a plastically deformed long-period stacking ordered magnesium alloy. J. Alloy Compd. 771, 629-635. doi: 10.1016/j.jallcom.2018.08.313

Farkas, G., Máthis, K., Pilch, J., Minárik, P., Lukáš P., and Vinogradov, A. (2017). Deformation behavior of Mg-alloy-based composites at different temperatures studied by neutron diffraction. Mater. Sci. Eng. A 685, 284-293. doi: 10.1016/j.msea.2017.01.010

Garcés, G., Máthis, K., Medina, J., Horváth, K., Drozdenko, D., Oñorbe, E., et al. (2018). Combination of in-situ diffraction experiments and acoustic emission testing to understand the compression behavior of $\mathrm{Mg}$-Y- $\mathrm{Zn}$ alloys containing LPSO phase under different loading conditions. Int. J. Plastic. 106, 107-128. doi: 10.1016/j.ijplas.2018.03.004

Gharghouri, M. A., Weatherly, G. C., Embury, J. D., and Root, J. (1999). Study of the mechanical properties of $\mathrm{Mg}-7.7 \mathrm{at} \% \mathrm{Al}$ by in-situ neutron diffraction. Philos. Mag. A 79, 1671-1695. doi: 10.1080/01418619908210386

Guan, D., Liu, X., Gao, J., Ma, L., Wynne, B. P., and Rainforth, W. M. (2019). Exploring the mechanism of "Rare Earth" texture evolution in a lean $\mathrm{Mg}-\mathrm{Zn}$ Ca alloy. Sci. Rep. 9:7152. doi: 10.1038/s41598-019-43415-z

Hagihara, K., Kinoshita, A., Sugino, Y., Yamasaki, M., Kawamura, Y., Yasuda, H. Y., et al. (2010a). Effect of long-period stacking ordered phase on mechanical properties of Mg97Zn1Y2 extruded alloy. Acta Mater. 58, 6282-6293. doi: 10.1016/j.actamat.2010.07.050

Hagihara, K., Yokotani, N., and Umakoshi, Y. (2010b). Plastic deformation behavior of $\mathrm{Mg} 12 \mathrm{YZn}$ with 18R long-period stacking ordered structure. Intermetallics 18, 267-276. doi: 10.1016/j.intermet.2009.07.014

Heiple, C. R., and Carpenter, S. H. (1987a). Acoustic emission produced by deformation of metals and alloys - a review: part I. J. Acoustic Emission 6, 177-204.

Heiple, C. R., and Carpenter, S. H. (1987b). Acoustic emission produced by deformation of metals and alloys - a review: part II. J. Acoust Emission 6, 215-237.

Inoue, A., Kawamura, Y., Matsushita, M., Hayashi, K., and Koike, J. (2001). Novel hexagonal structure and ultrahigh strength of magnesium solid solution in the Mg-Zn-Y system. J. Mater. Res. 16, 1894-1900. doi: 10.1557/JMR.2001.0260
Jono, Y., Yamasaki, M., and Kawamura, Y. (2013). Effect of LPSO phase-stimulated texture evolution on creep resistance of extruded $\mathrm{Mg}-\mathrm{Zn}-\mathrm{Gd}$ Alloys. Mater. Trans. 54, 703-712. doi: 10.2320/matertrans.MI201218

Kawamura, Y., Hayashi, K., Inoue, A., and Masumoto, T. (2001). Rapidly solidified powder metallurgy $\mathrm{Mg}_{97} \mathrm{Zn}_{1} \mathrm{Y}_{2}$ alloys with excellent tensile yield strength above $600 \mathrm{MPa}$. Mater. Trans. 42, 1172-1176. doi: 10.2320/matertrans.42.1172

Kawamura, Y., Kasahara, T., Izumi, S., and Yamasaki, M. (2006). Elevated temperature $\mathrm{Mg} 97 \mathrm{Y} 2 \mathrm{Cu} 1$ alloy with long period ordered structure. Scr. Mater. 55, 453-456. doi: 10.1016/j.scriptamat.2006.05.011

Kishida, K., Inoue, A., Yokobayashi, H., and Inui, H. (2014). Deformation twinning in a $\mathrm{Mg}-\mathrm{Al}-\mathrm{Gd}$ ternary alloy containing precipitates with a long-period stacking-ordered (LPSO) structure. Scr. Mater. 89, 25-28. doi: 10.1016/j.scriptamat.2014.06.019

Mathis, K., Chmelik, F., Janecek, M., Hadzima, B., Trojanova, Z., and Lukac, P. (2006). Investigating deformation processes in AM60 magnesium alloy using the acoustic emission technique. Acta Mater. 54, 5361-5366. doi: $10.1016 /$ j.actamat.2006.06.033

Matsumoto, R., Uranagase, M., and Miyazaki, N. (2013). Molecular dynamics analyses of deformation behavior of long-period-stacking-ordered structures. Mater. Trans. 54, 686-692. doi: 10.2320/matertrans.MI201211

Mayama, T., Noda, M., Chiba, R., and Kuroda, M. (2011). Crystal plasticity analysis of texture development in magnesium alloy during extrusion. Int. J. Plastic. 27, 1916-1935. doi: 10.1016/j.ijplas.2011.02.007

Oñorbe, E., Garcés, G., Pérez, P., and Adeva, P. (2012). Effect of the LPSO volume fraction on the microstructure and mechanical properties of $\mathrm{Mg}-\mathrm{Y} 2 \mathrm{X}-\mathrm{Zn} \mathrm{X}$ alloys. J. Mater. Sci. 47, 1085-1093. doi: 10.1007/s10853-011-5899-4

Sillekens, W. H., and Bohlen, J. (2012). "Hydrostatic extrusion of magnesium alloys," in Advances in Wrought Magnesium Alloys - Fundamentals of Processing, Properties and Applications, eds C. Bettles and M. Barnett (Sawston, UK: Woodhead Publishing), 323-345.

Toronchuk, J. P. (1977). Acoustic emission during twinning of Zinc single crystals. Mater. Eval. 35, 51-53.

Vinogradov, A., Vasilev, E., Seleznev, M., Máthis, K., Orlov, D., and Merson, D. (2016). On the limits of acoustic emission detectability for twinning. Mater. Lett. 183, 417-419. doi: 10.1016/j.matlet.2016.07.063

Vinogradov, A., Yasnikov, I. S., and Merson, D. L. (2019). Phenomenological approach towards modelling the acoustic emission due to plastic deformation in metals. Scr. Mater. 170, 172-176. doi: 10.1016/j.scriptamat.2019.06.011

Yamasaki, M., Hashimoto, K., Hagihara, K., and Kawamura, Y. (2011). Effect of multimodal microstructure evolution on mechanical properties of $\mathrm{Mg}-\mathrm{Zn}-\mathrm{Y}$ extruded alloy. Acta Mater. 59, 3646-3658. doi: 10.1016/j.actamat.2011.02.038

Conflict of Interest: The authors declare that the research was conducted in the absence of any commercial or financial relationships that could be construed as a potential conflict of interest.

Copyright (C) 2019 Máthis, Drozdenko, Németh, Harjo, Gong, Aizawa, Yamasaki and Kawamura. This is an open-access article distributed under the terms of the Creative Commons Attribution License (CC BY). The use, distribution or reproduction in other forums is permitted, provided the original author(s) and the copyright owner(s) are credited and that the original publication in this journal is cited, in accordance with accepted academic practice. No use, distribution or reproduction is permitted which does not comply with these terms. 